\title{
IMPLIKASI FENOMENA ALAM DAN MISKOMUNIKASI RADIOTELEPHONY PADA KECELAKAAN PENERBANGAN: KAJIAN AEROLINGUISTIK
}

\author{
Implications of Natural Phenomenas And Radiotelephony Miscommunications in \\ Flight Accidents: Aerolinguistic Study
}

\author{
Rani Siti Fitriani \\ Pascasarjana Universitas Pasundan \\ Jalan Sumatra No. 41 Babakan Ciamis Kec. Sumur Bandung \\ Kota Bandung, Jawa Barat 40117 \\ E-mail: ranisitifitriani19@gmail.com
}

\begin{abstract}
The phenomenon of airplane accidents is caused by various factors. According to the Federal Aviation Administration (FAA) there are three factors causing accidents, namely weather (weather) at 13.2\%, the fleet (aircraft) used by $27.1 \%$ and nearly $66 \%$ of all accidents and incidents. flight caused by humans (human factors). Aerolinguistic studies will dissect how weather factors or natural phenomena and human factors such as radiotelephony miscommunication are a factor in aviation accidents. Miscommunication in radiotelephony between pilots and ATC or APP can be dissected using aerolinguistic study (Fitriani, 2019) with the ICAO Annex in aeronautics and pragmatics in linguistics i.e., the theory of the Grice Cooperation Principle. The research method used is descriptive qualitative method. Based on the results of the study, it is known that the GIA 152 plane crash (1997) in Buah Nabar, North Sumatra and the crash of a Boeing 747 plane crash, KLM flight 4805 and Pan Am flight 1736 (1977) on the runway of Los Rodeos Airport in Tenerife, Spain, occurred due to weather or natural and human factors, namely a misunderstanding in radiotelephony communication between the pilot, ATC, and APP.
\end{abstract}

Keywords: Aerolinguistics, accidents aircraft, weather, miscommunication

\begin{abstract}
Abstrak
Fenomena kecelakaan pesawat terbang disebabkan oleh beragam faktor. Menurut Federal Aviation Administration ( $F A A$ ) ada tiga faktor penyebab kecelakaan, yaitu cuaca (weather) sebesar 13,2 \%, armada (pesawat) yang digunakan sebesar 27,1\% dan hampir $66 \%$ dari keseluruhan kecelakaan (accidents) maupun insiden (incidents) penerbangan disebabkan manusia (human factors). Kajian Aerolinguistik akan membedah bagaimana faktor cuaca atau fenomena alam dan faktor manusia seperti miskomunikasi radiotelephony menjadi faktor penyebab kecelakaan penerbangan. Miskomunikasi dalam radiotelephony antara pilot dan ATC atau APP dapat dibedah dengan menggunakan kajian Aerolinguistik dengan ICAO Annex dalam aeronautika dan pragmatik dalam linguistik yakni, teori Prinsip Kerja Sama Grice. Metode penelitian yang dilakukan adalah metode deskriptif kualitatif. Berdasarkan hasil penelitian diketahui bahwa kecelakaan pesawat GIA 152 (1997) di Buah Nabar Sumatera Utara dan kecelakaan tabrakan tabrakan pesawat Boeing 747, KLM penerbangan 4805 dan Pan Am penerbangan 1736 (1977) di landasan pacu Bandar Udara Los Rodeos di Tenerife Spanyol, terjadi karena faktor cuaca atau alam dan manusia yakni kesalahpahaman dalam konevrsasi radiotelephony antara pilot, ATC, dan APP.
\end{abstract}

Kata Kunci: Aerolinguistik, kecelakaan pesawat, cuaca, miskomunikasi 


\section{PENDAHULUAN}

Kecelakaan pesawat Sriwijaya no penerbangan SJ182 tipe B737-500, nomor registrasi PKCLC, dan route WIII-WIOO pada Sabtu, 9 Januari 2021 yang lepas landas dari Bandara Seokarno Hatta pada pukul 14.14 WIB menuju Bandara Supadio, dan direncanakan tiba pada pukul 15.50 WIB, menjadi berita duka awal tahun 2021. Pesawat Sriwijaya SJ182 tipe B737-500, nomor registrasi PKCLC jatuh di Pulau Laki Kelurahan Pulau Pari, Kecamatan Kepulauan Seribu Selatan, Kabupaten Kepulauan Seribu, DKI Jakarta, dengan jumlah korban yang meninggal 62 orang terdiri dari, 50 orang penumpang, 6 orang kru aktif, dan 6 orang ekstra kru penerbangan. Sejak terjadinya kecelakan pesawat Sriwijaya SJ182 dilakukan pencarian kotak hitam, serpihan kotak puing pesawat, juga jasad korban oleh tim SAR dibantu relawan dari TNI AL, Polri, relawan Persatuan Olahraga Selam Seluruh Indonesia (POSSI), dan yang lainnya.

Banyak faktor yang menjadi penyebab kecelakaan pesawat terbang yaitu, faktor manusia, teknis, lingkungan atau cuaca, dan fasilitas. Menurut Database KNKT 2010-2016, persentase kecelakaan yang disebabkan oleh faktor manusia mencapai $67,12 \%$, faktor teknis $15,75 \%$, faktor lingkungan $12,33 \%$, dan faktor fasilitas 4,79\%. Menurut Federal Aviation Administration (FAA) terdapat tiga faktor penyebab kecelakaan, yaitu faktor cuaca (weather) sebesar 13,2 \%, armada (pesawat) yang digunakan sebesar 27,1 \% dan hampir 66\% dari keseluruhan kecelakaan (accidents) maupun insiden (incidents) penerbangan disebabkan kesalahan manusia (human factors) WILCO: I understand your message and will comply with it an error) dalam mengoperasikan sistem penerbangan itu sendiri (Susetyadi, et.al. 2008).

Faktor lingkungan, atau cuaca sangat dipengaruhi kondisi alam. Saat terjadi bencana lama maka akan berpengaruh besar pada keselamatan penerbangan. Adakalanya, penerbangan ditunda sampai kondisi alam memungkinkan menjadi aru lalu lintas udara pesawat dari bandara yang satu ke bandara lainnya. Namun, tanpa dipungkiri dampak dari benca alam yang terjadi pada akhirnya berpengaruh besar pada suatu penerbangan. Menurut Undang-Undang Nomor 24 Tahun 2007 ada beberapa klasifikasi bencana alam yaitu (1) Bencana alam yaitu bencana yang diakibatkan oleh peristiwa atau serangkaian peristiwa yang disebakan oleh alam seperti gempa bumi, tsunami, gunung meletus, banjir, kekeringan, angin topan, dan tanah longsor; (2) Bencana nonalam yaitu bencana yang diakibatkan oleh peristiwa atau rangkain peristiwa yang disebabkan oleh gagal teknologi, gagal modernisasi, efidemi, dan wabah penyakit; dan (3) Bencana sosial yaitu peristiwa atau serangkaian peristiwa yang disebabkan oleh manusia yang meliputi konflik sosial antarkelompok atau antarkomunitas masyarakat, dan teror.

Dalam suatu kecelakaan pesawat terbang, kotak hitam menjadi benda yang paling penting dan dicari KNKT untuk diinvestigasi. Meskipun namanya kotak hitam tetapi warnanya justru oranye dan dibuat dari alumunium dengan lapisan insulasi yang berfungsi melindungi peranti dari suhu tinggi dan bagian luar berbahan titanium atau baja sehingga kotak hitam tidak akan mudah hancur atau rusak (Gambar 1). Kotak 
hitam merekam percakapan terakhir sebelum kecelakaan pesawat terjadi. Setiap pesawat memiliki dua kotak hitam yaitu, Flight Data Recorder (FDR) 'perekam data penerbangan' dan Cockpit Voice Recorder (CVR) 'perekam percakapan pilot' antara pilot, kopilot, pemandu lalu lintas udara (ATC atau APP), dan kru penerbangan lainnya. Pada rekaman kotak hitam tersebut, tidak hanya suara percakapan radiotelphony antara pilot, kopilot, pemandu lalu lintas udara saja yan terekamn tetapi juga suara desing mesin pesawat atau suara yang lainnya akan terekam.

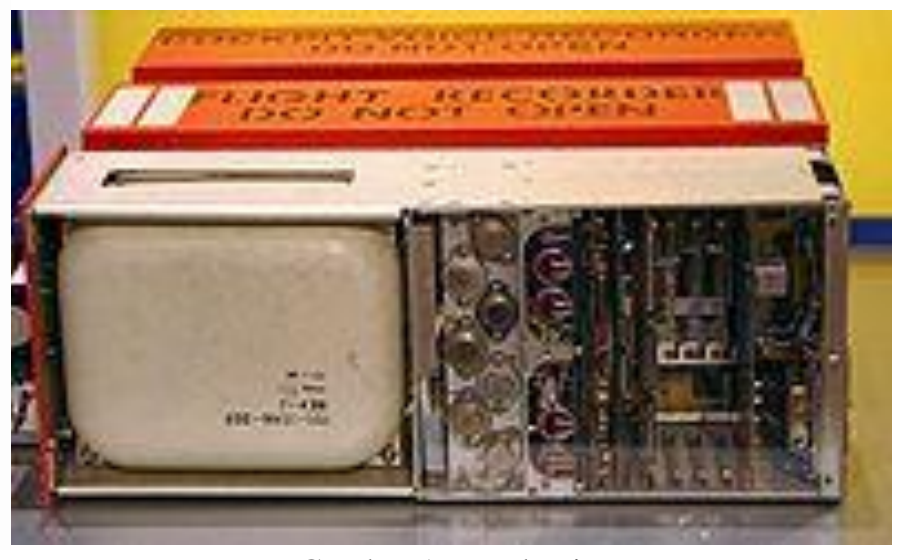

Gambar 1. Kotak Hitam

Sumber: https://commons.wikimedia.org/wiki/File:Black_box.aeroplane.JPG

Percakapan radiotelephony antara pilot dan pemandu lalu lintas udara (ATC dan APP) dilakukan dengan menggunakan radio VHF sejak konteks menyalakan mesin pesawat 'start engine', kemudian konteks terbang 'flight' sampai konteks mendarat 'landing'. Percakapan radiotelephony diawali dengan tuturan pilot memanggil dan menyapa ATC, kemudian ATC menjawab panggilan dan sapaan pilot juga mempersilakan pilot untuk menyampaikan tuturannya berupa infomasi mengenai tujuan penerbangan, jumlah penumpang, level ketinggian pesawat, dan sebagainya. Proses komunikasi dalam percakapan radiotelephony ini merupakan proses komunikasi interaksi karena tuturan dari peserta tutur akan meminta umpan balik 'feedback' dari peserta tutur lainnya. Artinya, setelah pilot bertutur ia meminta umpan balik 'feedback' dari ATC begitu pun setelah ATC bertutur ia meminta umpan balik 'feedback' dari pilot. Proses komunikasi interaksi tersebut berbentuk komunikasi dua arah dari penutur kepada mitra tutur dan dari mitra tutur penutur.

Setiap kali pilot akan melakukan suatu tindakan atau kegiatan menjalankan pesawat maka ia harus melapor, meminta izin, juga meminta instruksi atau perintah dari ATC sebagai pengatur lalu lintas udara. Begitupun ATC harus memberikan tuturan yang jelas, informatif, efektif, efesien, dan tidak ambiguitas kepada pilot agar mudah dipahami sehingga tidak terjadi kesalahpahaman. Bahasa yang digunakan dalam percakapan radiotelephony adalah bahasa Inggris. Konversasi aeronautika radiotelephony harus mengacu pada konvesi yang digunakan dalam dunia aeronautika yaitu International Civil Aviation Organization (ICAO) Annex 10 volume II tentang Aeronautical Telecomunications-Communication Procedures including those with 
PANS status, sixth Edition, July 2014; ICAO Manual of Radiotelephony fourth Edition, 2007; dan ICAO Doc 4444 Air Trafic Management sixteenth Edition, 2016. Hal yang paling penting dalam percakapan radiotelephony adalah pemakaian readback yang harus dilakukan oleh pilot.

Dalam ICAO Annex 10 poin 4.5.7.5 dijelaskan bahwa Readback of clearance "The flight crew shall readback to the traffic controller safety-related party of ATC clearances and instructions which are transmitted by voice. The following items shall always be readback". Permintaan izin dengan mengulang kembali tuturan 'Kru penerbangan akan mengulang kembali tuturan untuk mengontrol/menjaga keselamatan penerbangan dengan tuturan meminta izin kepada ATC dan meminta arahan akan apa yang harus dilakukannya menggunakan/dengan suara/tutura. Item-item tersebut akan selalu di-readback. Saat ATC memerintah pilot untuk belok ke kiri maka pilot harus mengulang tuturan tersebut kemudian setelah ATC memberikan izin untuk belok kiri maka pilot kembali melakukan mengulang kembali 'readback' tuturan pemberian izin ATC tersebut sambil melakukan apa yang diperintahkan oleh ATC yaitu melakukan pergerakan pesawat membelok ke kiri. Pilot harus mengulang kembali tuturan perintah/instruksi ATC. Tuturan ulangan pilot yang disebut dengan readback' tuturan ATC dan memberikan laporan kepada ATC setiap melakukan apa yang diperintah atau diarahkan oleh ATC.

Pragmatik merupakan ilmu bahasa yang mengkaji pemakaian bahasa sebagai alat komunikasi penutur dengan mitra tutur dalam suatu peristiwa tuturan. Grice mengelompokkan prinsip kerja sama menjadi empat maksim. Saat peserta tutur melaksanakan prinsip kerja sama maka komunikasi akan berjalan dengan efektif, efesien, dan pesan yang disampaikan dapat dipahami dengan baik oleh peserta tutur. Dalam konversasi radiotelephony, pilot, kopilot, ATC, dan APP harus dapat berkomunikasi dan memberikan informasi yang cukup, relatif memadai, dan seinfo rmatif mungkin dalam percakapan. Berikut empat Prinsip Kerja Sama Grice:

(1) Maksim Kuantitas

Penutur diharapkan dapat memberikan informasi yang cukup, relatif memadai, dan seinformatif mungkin dalam percakapan dan tidak boleh memberikan informasi lebih dari apa yang dibutuhkan mitra tutur Wardhaugh (2009). Dengan kata lain, tuturan yang tidak mengandung informasi yang diperlukan mitra tutur dalam suatu percakapan atau peristiwa tutur maka disebut melanggar maksim kuantitas, begitupun sebaliknya (Rahardi: 2007).

(2) Maksim Kualitas

Penutur diharapakan dapat menyampaikan sesuatu yang nyata dan sesuai dengan fakta yang sebenarnya di dalam aktivitas bertutur. Menurut Wardhaugh (2009) maksim kualitas merupakan cara dengan bentuk 'sugar-coating'. Artinya, prinsip untuk membalut informasi yang tidak tepat dengan cara diubah atau dimaniskan ada yang menyebutnya sebagai 'white lies' atau bohong untuk kebaikan. Pelanggaran maksim ini untuk mengoptimalkan dan menyempurnakan relasi dalam komunikasi (Rahardi: 2009). 
(3) Maksim Relevansi

Penutur dan mitra tutur dituntut untuk bertutur dengan menjalin kerja sama yang baik sehingga relevan dengan objek pembicaraan. Bertutur yang tidak memberikan konstribusi yang relevan itu akan dianggap tidak mematuhi prinsip kerja sama Grice (Rahardi 2007: 56).

(4) Maksim Pelaksanaan

Penutur dan mitra tutur dalam bertutur dituntut untuk menyampaikan informasi secara langsung, jelas, teratur, tidak sama, singkat, menghindari ambiguitas, dan ketidakjelasan ekspresi (Warhaugh, 2009: 291).

Saat pilot atau kopilot mengalami situasi kondisi darurat dapat digunakan beberapa kategori pesan yang digunakan untuk kondisi darurat atau emergensi di penerbangan. Tnetunya, penggunaan pesan emergensi dalam konversasi radiotelephony tersebut tidak sama dengan tidak sama dengan penggunaan pesan emergensi pada konversasi di transportasi darat seperti kereta api dan bus. Berikut kategori yang digunakan dalam radiotelephony (Tabel 1).

Tabel 1. Kategori pesan dalam radiotelephony

\begin{tabular}{|c|c|c|}
\hline No & $\begin{array}{l}\text { Kategori pesan sesuai dengan } \\
\text { Kondisi yang diprioritaskan }\end{array}$ & Kode Radiotelepony \\
\hline 1 & $\begin{array}{l}\text { Distrsess calls, distress messages, dan distress } \\
\text { traffic } \\
\text { (panggilan darurat, pesan darurat, dan lalu intas } \\
\text { udara darurat) }\end{array}$ & $M A Y D A Y$ \\
\hline 2 & $\begin{array}{l}\text { Urgency messages, including messages preceded } \\
\text { by the medical transport signal } \\
\text { (panggilan penting, termasuk pesan yang } \\
\text { didahulukan untuk tanda pesawat medis) }\end{array}$ & $\begin{array}{l}A N, \quad P A N, \text { or PAN, PAN } \\
M E D I C A L\end{array}$ \\
\hline
\end{tabular}

\section{HASIL DAN PEMBAHASAN}

Kecelakaan pesawat Garuda Airways 152 jenis Airbus A300-B4 PK-GAI dalam penerbangan dari Soekarno Hatta Bandara Internasional ke Bandara Polonia Medan pada tanggal 26 September 1997, terjadi di Desa Buah Nabar Sumatera Utara dan memakan korban 234 orang semua kru penerbangan dan penumpang meninggal dunia. Saat itu, kondisi awan yang diselimuti oleh asap kebakaran hutan sehingga jarak pandang terganggu. Sebelum terjadi kecelakaan berdasarkan rekaman dari kotak hitam percakapan radiotelephony antara pilot, kopilot, dan APP terjadi kebingungan pilot saat mendapatkan arahan dari APP dalam menentukan arah belok antara ke kiri dan ke kanan.

Pada Jumat, 26 Sepetember 1997 terjadi kecelakaan pesawat Garuda Airways 152 jenis Airbus A300-B4 PK-GAI dalam penerbangan dari Soekarno Hatta Bandara Internasional ke Bandara Polonia Medan di Desa Buah Nabar Sumatera Utara (Gambar 2) yang menyebabkan meninggal 234 orang terdiri dari kru penerbangan dan 
penumpang. Saat itu, kondisi awan di Desa Buah Nabar diselimuti oleh asap kebakaran hutan sehingga jarak pandang pilot dan kopilot pesawat GIA 152 A300-B4 PK-GAI menjadi terganggu. Fenomena alam yang tidak seperti dalam situasi kondisi cuaca normal. Sebelum terjadi kecelakaan berdasarkan rekaman dari kotak hitam percakapan radiotelephony, APP sebagai pemandu lalu lintas udara sempat salah menyebutkan call number atau nama panggilan pilot pesawat yang satu dengan yang lainnya karena arus lalu lintas udara saat itu cukup padat. Oleh karena itu, sempat terjadi pula kesalahpahaman antara pilot, kopilot, dan APP dalam konversasi radiotelphony (Bagan 1).

(1) Tower APP:

"Indonesia 152 turn right heading 046 report established

Localizer."

$\underline{\text { Indonesia }} \underline{1} \underline{5} \quad \underline{2}$ turn right heading

$\underline{0}$

'Indonesia' 'satu' 'lima' 'dua' 'belok' 'kanan' 'arah' 'nol'

$4 \quad \underline{6}$ report established localizer

'empat' 'enam' 'lapor' 'stabil ‘ 'perlokolisasi'

'Indonesia satu lima dua, belok kanan arah nol empat enam laporkan established localizer ${ }^{4}$,

(2) Kopilot GIA 152:

"Turn right heading 040 derajat Indonesia 152 check Established."

$\underline{\text { Turn }}$ right heading $\underline{0} \underline{4} \underline{0}$ derajat Indonesia

'belok' 'kanan' 'arah' 'nol' 'empat' 'nol' 'derajat' 'Indonesia'

152 check Established

'satu' 'lima' 'cek' 'stabil'

'Belok kanan arah nol empat nol Indonesia satu lima dua cek saat sudah pada posisinya, sesuai yang diinstruksikkan oleh ATC'

(3) Kapten GIA 152:

"Indonesia 152 confirm turning left or turning right heading046?"

$\underline{\text { Indonesia }} \quad \underline{1} \quad \underline{5} \quad \underline{2}$ confirm turning left

'Indonesia' 'satu' 'lima' 'dua' 'konfirmasi' 'berputar' 'kiri'

$\underline{\text { or }}$ turning right heading $\underline{0} \quad \underline{4} \quad \underline{6}$

'atau' 'berputar' 'kanan' 'arah' 'nol' 'empat' 'enam'

'Indonesia satu lima dua konfirmasi belok ke kiri atau ke kanan

arah nol empat enam'

(4) Tower APP:

"Turning right Sir."

Turning $\underline{\text { right }} \underline{\text { Sir }}$

'berputar' 'kanan' 'Pak'

'berputar ke kanan Pak' 
(8) Kapten Pilot:

"Roger 152."

$\underline{\text { Roger }} \underline{1} \underline{5} \quad \underline{2}$

'roger' 'satu' 'lima' 'dua'

'roger satu lima dua'

(9) Tower APP:

"152 confirm you are making turn left now?"

$\underline{1} \underline{5} \underline{2}$ confirm you are making

'satu' 'lima' 'dua' 'konfirmasi' 'kamu' 'Ø ' 'membuat'

turn left now

'belok' 'kiri' 'sekarang'

'satu lima dua kamu berbalik kanan sekarang'

(10) Kapten GIA 152:

"Affirm."

Affirm

'benar'

(11) Tower APP:

"152 continue left turn now."

$\underline{1} \underline{5} \underline{2}$ continue left turn now

'satu' 'lima' 'dua' 'lanjutkan' 'kiri' 'belok' 'sekarang'

'satu lima dua lanjutkan belok kiri sekarang'

(12) Kapten GIA 152:

"Err ... confirm turning left? We are start turning right now."

$\underline{\text { Err }}$ confirm turning left We are start

' $\varnothing$ ' 'konfirmasi' 'berputar' 'kiri' 'kita' ' $\varnothing$ ' 'mulai'

turning right now

'berputar' 'kanan' 'sekarang'

'Konfirmasi kamu belok belok ke kiri sekarang'

(13) Tower APP:

"Indonesia 152 continue turn right heading 015."

$\underline{\text { Indonesia }} \underline{1} \underline{5} \underline{2}$ continue turn right

'Indonesia' 'satu' 'lima' 'dua' 'lanjutkan' 'belok' 'kanan'

heading $\underline{0} \underline{1} \underline{5}$

'arah' 'nol' 'satu' 'lima'

'Indonesia satu lima dua lanjutan belok kakan arah nol satu lima'

(Sumber Final Report KNKT)

\section{Konteks:}

Approach Control Office (APP) Polonia sedang mengatur beberapa pilot pesawat yaitu, Garuda 152; Bouroq 683; dan Merpati. Saat itu APP Polonia tidak terlalu fokus mengatur dan meminta konfirmasi arah belok dari beberapa pesawat. APP Polonia menanyakan atau 
meminta konfirmasi arah belok dari pilot pesawat Garuda 152 kemudian pilot menjawab dan meminta arahan dari APP Polonia.

Bagan 1. Transkrip percakapan pilot GIA 152 A300-B4 PK-GAI dan APP yang terekam dalam kotak hitam (Sumber: Final Report KNKT).
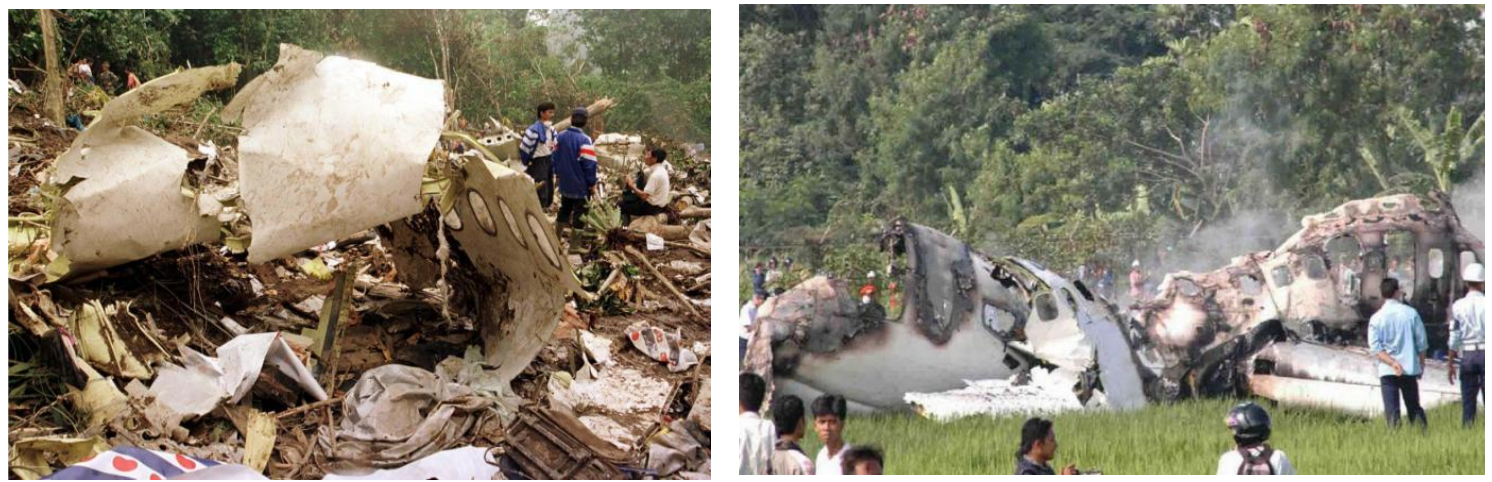

Gambar 2. Kondisi Pesawat AirbusA300-B4 GIA 152 di Buah Nabar, Deli Serdang, Sumatera Utara (Sumber: liputan6.com).

Pada 27 Maret 1977, terjadi kecelakaan tabrakan pesawat Boeing 747, KLM penerbangan 4805 dan Pan Am penerbangan 1736 di landasan pacu Bandar Udara Los Rodeos di Tenerife Spanyol. Akibatnya, 583 orang meninggal dunia, 61 orang cedera dan selamat. Musibah kecelakaan pesawat tersebut telah memakan korban jiwa paling banyak di dunia sepanjang sejarah. Kondisi cuaca yang buruk saat itu menjadi salah satu penyebab kecelakaan pesawat. Pesawat KLM jenis Boeing 747-2068 PH-BUF lepas landas di Bandara Schiphol Amsterdam Belanda menuju Bandara Gran Canaria Kepulauan Canaria, Spanyol dengan jumlah penumpang 234 orang dan jumlah kru penerbangan 14 orang.

Seluruh penumpang dan kru penerbangan meninggal dunia, tidak ada yang selamat. Pesawat Pan Am jenis Boeing 747-121 Nomor registrasi N736PA lepas landas dari Bandara Los Angeles, Amerika Serikat menuju Bandara Gran Canaria, Kepulauan Canaria, Spanyol dan transit di Bandara John F. Kennedy, New York, Amerika Serikat dengan penumpang 380 orang dan kru penerbangan 16 orang. Jumlah korban yang meninggal akibat tabrakan pesawat adalah 335 orang yang terdiri dari 326 orang penumpang dan 9 orang kru penerbangan. Sebanyak 61 orang dinyatakan cedera dan selamat dari tragedi kecelakaan pesawat di Bandara Tenerife, Spanyol. Berikut adalah percakapan pilot KLM dan ATC yang terekam dalam kotak hitam (Bagan 2):

\section{P KLM-4805: "We are now take off." \\ 'Kami sekarang akan mendarat' \\ ATC Tenerife: "Ok, stand by for take-off. We will call you." \\ 'Ya, menunggu untuk tinggal landas. Kami akan memanggilmu'}

Bagan 2. Transkrip percakapan pilot KLM dan ATC yang terekam dalam kotak hitam 
Tuturan $O k$ yang diucapkan ATC maksudnya agar PILOT KLM-4805 menunggu untuk tinggal landas 'stand by for take-off'. Namun, Pilot justru memahaminya iya 'Ok' untuk clearance take off dan pilot pun tidak mengulang ucapan ATC 'readback' tetapi langsung melakukan clearance take off atau clear for take off. Kesalahpahaman tersebut dapat dihindari apabila ATC langsung saja menjawab menunggu untuk tinggal landas 'stand by for take off' untuk menyatakan apabila dia mengerti perintah dari ATC dan yakin bahwa landasannya kosong atau aman. Namun, saat itu pilot KLM-4805 langsung melepas rem dan pesawat Pan AM 1736 sedang melakukan taxiback ke titik tinggal landas 'take off'. ATC Tenerife tidak fokus mengatur dan mengarahkan pergerakan pesawat KLM-4805 dan Pan AM 1736. Akibatnya, terjadi tabrakan besar yang menyebabkan seluruh penumpang KLM-4805 sebanyak 248 orang tewas, sementara di pihak PanAm-1736, 326 penumpang dan 9 awak tewas. Total korban dari kedua pesawat adalah 583 orang. Tragedi Tenerife merupakan kecelakaan terbesar sepanjang sejarah (Gambar 3).

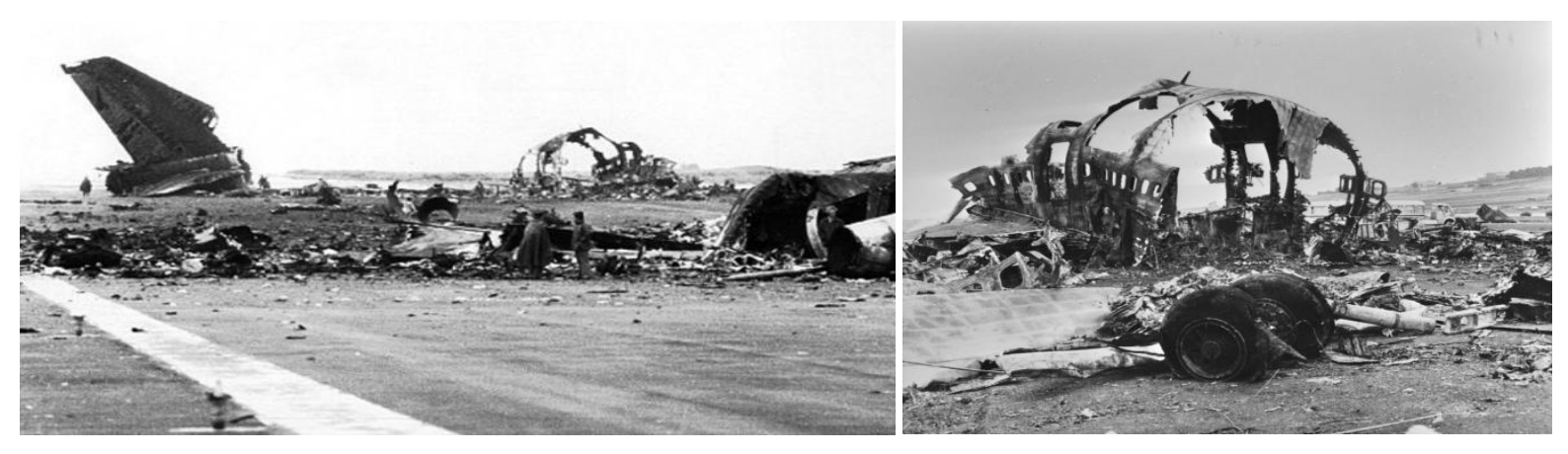

Gambar 3. Kondisi Pesawat KLM dan Pesawat Pan Am di Landasan Bandara Los Rodeoa di Tenerife setelah terjadi kecelakaan pesawat (1977) Sumber: liputan6.com dan Wikipedia

\section{SIMPULAN}

Dalam percakapan radiotelphony penting sekali pilot, kopilot, dan pemandu lalu lintas udara (ATC dan APP) menggunakan bahasa sesuai phraseology dan melaksanakan empat maksim kerja sama Grice yaitu, kuantitas, kualitas, relevansi, dan cara agar dapat menghindari kesalahpahaman dalam komunikasi yang dapat berakibat pada kecelakaan pesawat terbang. Hal penting lainnya dalam radiotelephony adalah readback untuk memastikan instruksi atau arahan dari APP atau ATC dipahami dengan baik oleh pilot juga menghindari kesalahpahaman dalam komunikasi yang dapat berakibat fatal pada penerbangan pesawat.

Setiap pilot harus memperhatikan dengan baik dari setiap tuturan perintah atau arahan. Begitupun ATC dan APP harus fokus dan konsentrasi saat memberikan perintah atau arahan kepada banyak pilot yang berada pada situasi kondisi dan rute yang berbeda. Apabila pilot tidak mengulang kembali dengan baik tuturan perintah atau arahan ATC atau APP 'readback' akan menyebabkan percakapan radiotelephony tidak berlangsung dengan baik. Dengan demikian, tindakan yang seharusnya dilakukan justru salah atau 
tidak sesuai prosedur dan hal tersebut sangat berbahaya untuk keselamatan penerbangan atau pergerakan pesawat baik di landasan saat pilot memanggil dan meminta izin menyalakan mesin pesawat kepada ATC, pilot melapor ke ATC saat akan atau sedang tinggal landas, pilot melapor kepada ATC saat menaikkan atau menurunkan ketinggian pesawat atau membelokkan arah pesawat saat terbang, atau saat pilot meminta izin dan melapor kepada ATC saat pesawat akan mendarat, dan konteks lainnya.

\section{DAFTAR PUSTAKA}

Annex 10 to the Convention on International Civil Aviation. (2001) Aeronautical Telecommunications (Volume I, II, III, and IV). 5-1, hlm. 5-22

Fitriani, Rani Siti. (2019). "Tindak Tutur dalam Konversasi Radiotelehphony Aeronautika: Kajian Pragmatik.” Disertasi. Pascasarajana Fakultas Ilmu Budaya. Universitas Padjadjaran, hlm. 102-133.

Grundy, Peter.(2000). Doing Pragmatics. London: Oxford University Press, 185-200.

Leech, Geoffery.2011Prinsip-Prinsip Pragmatik. Penerjemah M.D.D. Jakarta: UI Press, hlm. 30-35.

Levinson, Stephen C. (2012). Pragmatik. Diterjemahkan oleh Auzar dari Pragmatics. Pekanbaru. UR Press./1983. Pragmatics. Inggris: Cambridge, hlm. 50-53.

Nadar, F.X. Pragmatik dan Penelitian Pragmatik. Yogyakarta: Graha Ilmu,hlm. 32-26.

Rahardi, R. Kuntjana. 2005 Kesantunan Imperatif dalam Bahasa Indonensia. Jakarta: Erlangga, hlm. 25-35

Searle, John. (1969). Sppech Acts: An Essay in the Philosophy of Language. Cambridge: Cambridge University Press, hlm. 60-65

Wing 4 Lanud Atang Sendjaja Skadron Udara 8 "Flying Procedure SA-330 Puma" Skadron Udara 8."Normal Procedure Check List" Skadron Udara 8.

Wingdik Terbang Lanud Adi Sutjipto "Radio Telephony" Skadron Pendidikan Lanud Adi Sutjipto.

\section{Sumber Internet:}

http://knkt.go.id/ diakses 26 November 2020.

\section{HASIL DISKUSI}

Tidak Ada Pertanyaan 